\title{
XANTHOGRANULOMATOUS PYELONEPHRITIS: PRESENTATION AND SURGICAL COMPLICATIONS.
}

1. MBBS, FCPS

Associate Professor of Urology

2. MBBS, MS

Assistant Professor of Urology

3. MBBS

Postgraduate Trainee Registrar (Urology)

4. MBBS

Postgraduate Trainee Registrar (Urology)

5. MBBS

BMC \& Sandeman Teaching

Hospital Quetta.

6. MBBS, DMRD

Radiologist

7. MBBS, MS

Professor \& Head of Department

8. MBBS

PGR Urology

9. MBBS, DU, MS

Professor \& Ex-Head of Department

$1,2,4,5,6,7,8,9$

BMC \& Sandeman Teaching Hospital

Quetta.

Correspondence Address:

Dr. Masha Khan

Associate Professor of Urology

BMC \& Sandeman Teaching Hospital

Quetta.

mashakhan@hotmail.com

Article received on:

22/07/2019

Accepted for publication:

16/10/2019

\section{INTRODUCTION}

Xanthogranulomatous Pyelonephritis (XGP) is an uncommon chronic inflammatory disease of the kidney. In this a granulomatous reaction occurs to ch. infection often in the presence of chronic obstruction, resulting in a destructive mass that invades the renal parenchyma and adjacent organs. ${ }^{1}$

The granulomatous tissue contains lipid-filled foamy macrophages which appear yellow in pathological appearance; hence the term 'xantho' (Greek for yellow) is used in its name ${ }^{2,3}$ (Figure-1,2). Though common in fifth to sixth decade, it can occur at any age. Women are more frequently affected than men. ${ }^{4}$
Masha Khan ${ }^{1}$, Salahuddin ${ }^{2}$, Muhammad Anwar $^{3}$, Ali Nawaz ${ }^{4}$, Muhammad Shoaib $^{5}$, Abdul Samad ${ }^{6}$, Haq Nawaz ${ }^{7}$, Yaqoob Zarkoon ${ }^{8}$, Saadat Khan ${ }^{9}$

STACT: Objectives: To review and evaluate the clinical presentation \& surgical complication XGP who underwent surgery in the department of Urology of a tertiary care hospital from series, demonstrates that low socioeconomic status could be another risk factor for XPN. Early lagnosis and proper treatment of urolithiasis \& urinary tract infection is important to prevent Key words: Granulomatous Infection, Nephrectomy, Pyelonephritis, Urolithiasis.

Article Citation: Khan M, Salahuddin, Anwar M, Nawaz A, Shoaib M, Samad A, Nawaz H, Zarkoon Y, Khan S. Xanthogranulomatous pyelonephritis: Presentation and surgical complications. Professional Med J 2020; 27(7):1391-1395. DOI: 10.29309/TPMJ/2020.27.07.3965

The most common symptoms of patient with xanthogranulomatous pyelonephritis are flank pain and fever. ${ }^{5}$

Other complaints include palpable mass, voiding symptoms, anorexia and weight loss. Obesity and other conditions associated with metabolic syndrome may coexist at the time of presentation and may be contributing factors to the development of xanthogranulomatous pyelonephritis and poor outcomes associated with it. ${ }^{2}$

In the past, the preoperative diagnosis of XGN was notoriously difficult because of its nonspecific clinical presentation and nonspecific radiographic 
appearances. However the preoperative diagnosis has considerably been improved with the use of ultrasound and computed tomography. The typical features of XGP on CT \& Ultra Sound are unilateral renal enlargement with multiple hypo echoic areas, calyceal dilatation along with multiple calculi and extra renal extension of inflammatory changes ${ }^{6}$ (Figure-1). Their presence in a patient with constitutional symptoms and urinary tract infection should alert the urologist to the possibility of this uncommon condition. Radialogical findings diagnose \& classify XPN into three stages depending on the extension of the inflammation, namely: stage 1 (Nephric XPN), stage 2 (perinephric XPN), \& stage 3 (paranephric XPN). ${ }^{7}$

Surgery remains the mainstay for a definitive diagnosis and cure of xanthogranulomatous pylonephritis, requiring extirpation (nephrectomy) as the standard surgical technique. ${ }^{8,9} \mathrm{We}$ retrospectively reviewed the cases of XGP who underwent nephrectomy in our Urology Department with pathological documentation.

\section{MATERIAL \& METHODS}

This study was conducted at the Urology department, Sandeman Provincial Teaching Hospital, Quetta. We retrospectively reviewed case reports of patients of XGP who had been operated in our unit from July, 2011 to June, 2018. The record of patients was assessed regarding complete history including socioeconomic status and physical examination. The investigations done before surgery were complete blood count, ESR, blood sugar, renal function tests, liver function tests, urine $D / R$, urine culture \& sensitivity, ultrasonography, CT urography \& DTPA cintigraphy.

The flank sub costal or intercostal approach was used for surgery in all the cases. After nephrectomy, fluid/pus from the kidney was sent for culture \& sensitivity while the kidney as a whole was sent for histopathological examination. Intra-operative complications were recorded including excessive bleeding (arbitrarily estimated as $>1 / 5^{\text {th }}$ of circulating blood of an individual, as in an average adult $>1000 \mathrm{ml}$ and was roughly calculated/ judged by the number of used sponges + blood in suction machine). Postoperative complications were also recorded. The diagnosis of XGP was confirmed on the histopathological examination report of the removed kidney.

\section{RESULTS}

There were 42 patients in the current study. In these 25 (59.50\%) were female and 17 (40.50\%) were male. The mean age of the patients was 49.8 +/- 16.04 years. Vast majority (88.1\%) of patients were of low socio-economic status. The most common presentation was flank pain, which was present in $100 \%$ patients. Both fever \& dysuria was present in $64.28 \%$. Anorexia \& weight loss was present in $85.71 \%$ \& $83.33 \%$ respectively. In laboratory finding pyuria was present in $88.1 \%$, anemia in $71.42 \%$, azotemia \& abnormal liver enzymes were present in $14.3 \%$ each. The most common associated condition was renal calculai in $83.33 \%$, diabetes mellitus in $47.61 \%$ and hypertension in 38.09\% (Table-I). Although pyuria was present in $88.1 \%$ patients but urine culture was +ve only in $50.0 \%$ patients. However in $23.80 \%$ more patients, fluid/pus obtained from the affected kidneys intra-operatively, was culture positive. So the total percentage of positive culture raised to $73.81 \%$.

The remaining (26.19\%) had sterile pyuria. The organisms isolated on culture were Escherichia coli $35.48 \%$, Proteus $29.03 \%$, Klebsiella $16.13 \%$, Pseudomonaus $\quad 9.68 \%$ \& other organisms (including Staphylococcus \& Enterobacter) 9.68\% (Table-II). Intra-operative excessive bleeding, requiring more than one pint blood transfusion occurred in $3(9.68 \%)$ patients. Intra-operative adjacent organs/visceral injury also occurred in 3(9.68) patients. While intra-operative major vessel (Inferior vena cava) tear/injury occurred in 1 (2.38\%) patients. Regarding postoperative complications, septicemia occurred in 1 (2.38\%), wound infection in 8 (19.04\%) \& incisional hernia in 2 (4.76\%) Patients (Table-III). 


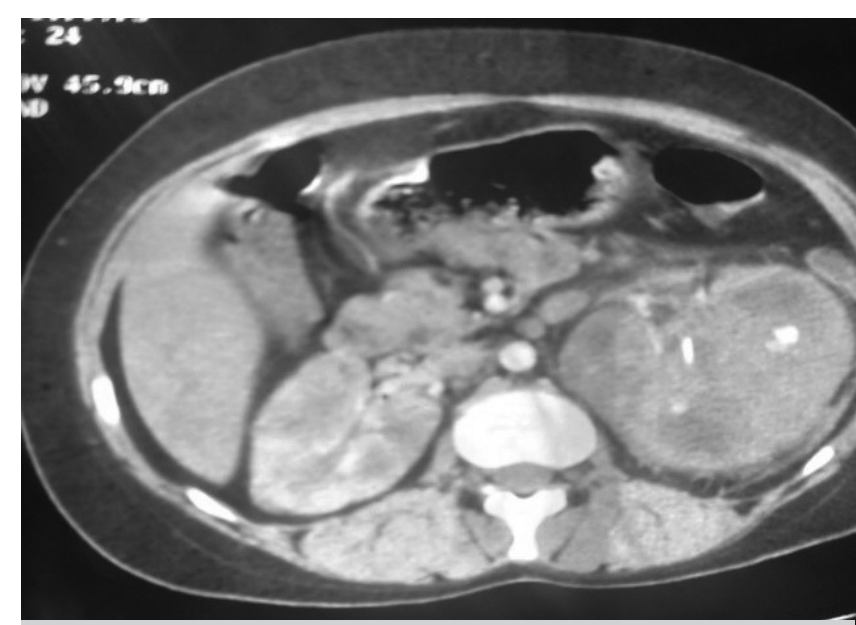

Figure-1

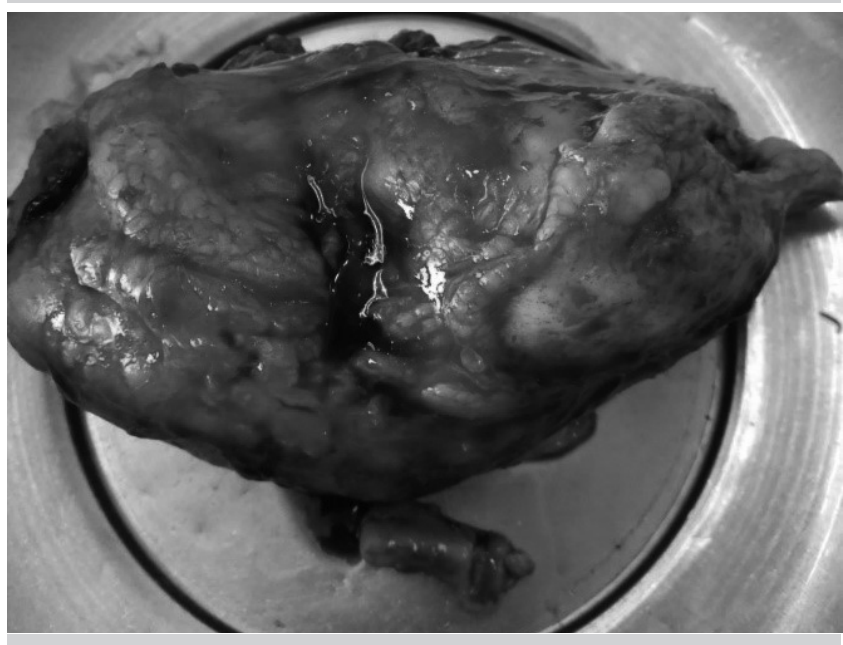

Figure-2

\begin{tabular}{|l|c|}
\hline \multicolumn{1}{|c|}{ Number of Patients \& (\%) } & $\mathbf{4 2}(\mathbf{1 0 0 )}$ \\
\hline Male \& (\%) & $17(40.4)$ \\
\hline Female \& (\%) & $25(59.5)$ \\
\hline Mean Age (years) & $49.8+/-18.6$ \\
\hline Flank pain (\%) & $42(100)$ \\
\hline Fever (\%) & $27(64.28)$ \\
\hline Dysuria (\%) & $27(64.28)$ \\
\hline Anorexia (\%) & $36(85.71)$ \\
\hline Weight loss (\%) & $35(83.33)$ \\
\hline Pyuria (\%) & $36(85.71)$ \\
\hline Anemia (\%) & $30(71.42)$ \\
\hline Haematuria (\%) & $21(50.00)$ \\
\hline Azotaemia (\%) & $6(14.30)$ \\
\hline Abnormal liver enzymes (\%) & $6(14.30)$ \\
\hline Associated renal calculai (\%) & $35(83.33)$ \\
\hline Associated diabetes mellitus (\%) & $20(47.61)$ \\
\hline Associated hypertension (\%) & $16(38.09)$ \\
\hline
\end{tabular}

Table-I. Patient's characteristics, laboratory findings and clinical presentation.

\begin{tabular}{|c|c|c|c|}
\hline \multicolumn{2}{|l|}{ No. } & \multicolumn{2}{|c|}{ (\%) } \\
\hline \multicolumn{2}{|l|}{ No growth } & \multicolumn{2}{|c|}{$11(26.19)$} \\
\hline \multicolumn{2}{|l|}{ +ve growth } & \multicolumn{2}{|c|}{$31(73.81)$} \\
\hline \multicolumn{2}{|l|}{ E-coli } & \multicolumn{2}{|c|}{$11(35.48)$} \\
\hline \multicolumn{2}{|l|}{ Proteus } & \multicolumn{2}{|c|}{$9(29.03)$} \\
\hline \multicolumn{2}{|l|}{ Klebsiella } & \multicolumn{2}{|c|}{$5(16.12)$} \\
\hline \multicolumn{2}{|l|}{ Pseudomonaus } & \multicolumn{2}{|c|}{$3(9.68)$} \\
\hline \multicolumn{2}{|c|}{$\begin{array}{l}\text { Others (Staphylococcus \& } \\
\text { Enterobacter species) }\end{array}$} & \multicolumn{2}{|c|}{$3(9.68)$} \\
\hline \multicolumn{4}{|c|}{$\begin{array}{l}\text { Table-II. Culture reports of urine }+ \text { fluid/pus from } \\
\text { affected kidney. }\end{array}$} \\
\hline Complications & \multicolumn{2}{|c|}{ No. of patients } & (\%) \\
\hline \multicolumn{4}{|c|}{ A: Intra-operative } \\
\hline Excessive bleeding & & 3 & (9.68) \\
\hline \multirow{2}{*}{$\begin{array}{l}\text { Adjacent organs/ } \\
\text { Visceral injury } \\
\text { Major vessels injury }\end{array}$} & & 3 & (9.68) \\
\hline & & 1 & (2.38) \\
\hline \multicolumn{4}{|c|}{ B: Post-operative } \\
\hline Septicemia & & 1 & $(2.38)$ \\
\hline Wound infection & & 8 & (19.04) \\
\hline Incisional hernia & & 2 & $(4.76)$ \\
\hline Reno-cutaneus fistula & & 1 & (2.38) \\
\hline
\end{tabular}

\section{DISCUSSION}

Although XPN is described in World literature, as a rare entity ${ }^{1,2}$, but in our region, where neglected long standing urolithiasis with improper treated recurrent urinary tract infection is a common happening, the condition is not so rare. In the last 7 years, in our department. 42 biopsy proven cases have been managed. There is still a high possibility of many cases of XPN being managed, un-diagnosed \& hence not included in the study. Although we did not use any specific tool to measure the socio-economic status of the patients, however by history \& general look, most of the patients were of far flung rural area, un-educated and of low socio-economic status. The mean age \& male female ratio of our patients is quite compareable to previous local studies. ${ }^{10}$ Women were affected more often than men. The frequent occurrence of XPN in females is most likely related to the higher incidence of urinary tract infection in women. Flank pain, pyuria, dysuria, low grade fever, anorexia \& weight loss was present understandably in majority 
of patients as in other series. ${ }^{10,11,12}$ Urinary tract obstruction either by urinary calculi or congenital malformation in children (ureteropelvic junction obstruction, vesico-ureteric reflux etc), is one of the important factor of this condition. Urinary calculai association with XPN has been described from 53 to $>83 \%$ in various previous series. ${ }^{1,11}$ Similarly $83.33 \%$ patients in our study had urinary calculai.

Although pyuria was present in $88.1 \%$ cases but urine culture reports were +ve only in $50.0 \%$ of patients. However in 10 (23.80\%) more patients fluid/pus obtained from the affected kidneys intraoperatively, was culture positive, hence raising the total culture positive cases to $73.81 \%$. These discrepancies between urine \& into-operative renal fluid cultures were most probably due to complete obstruction of the affected kidney, as described in previous series. ${ }^{12}$ It has been reported that more than half of the patients have sterile pyuria. ${ }^{11}$ The same was the case in our study where pyuria was present in $85.71 \%$, while urine culture was positive in only $52.38 \%$ of patients. The explanation of this sterile pyuria is most likely the prolong and repeated use of various antibiotics.

Regarding the isolated pathogens in XGP, many authors have found, Proteus mirabilis as the most common organism. ${ }^{10,13}$ Contrary to this, E-coli was the most common pathogen, in $35.48 \%$ and Proteus mirabilis was the $2^{\text {nd }}$ common pathogen in $29.03 \%$ cases. Ours these findings are supported by Kuo et al, who have described E-coli, as the most prevalent pathogen in $36.7 \%$ cases. ${ }^{14}$

Surgery of XPN can be difficult due to extensive adhesions as a result of inflammatory processes extending beyond the kidney. These factors contributetobothintra-operativeand postoperative complications. Intra-operatively we encountered 3 cases with excessive bleeding, one of them due to tear of inferior Vena Cava. All these patients needed intra-operative blood transfusions. In 2 patients colonic injury occurred on left side preoperatively, due to severe adhesions. One patient got pleural injury due to severe adhesions of the upper pole of right kidney, which required intercostal drain placement. Nearly same type of pattern and frequency of complications have been mentioned in previous series. ${ }^{14,16}$

Postoperatively the most common complication was wound infection in $8(19.04 \%)$ patients. All of them were treated by change of antibiotics and regular dressings. Out of these 3 patients needed simple re-suturing, while one patient developed incisional hernia and another one cutaneous (reno-cutaneous) fistula. These results are comparable to other series ${ }^{14,16}$ where open surgery has been carried out for XPN. However laparoscopic surgery has been mentioned to have minimized some of the complications of XPN. ${ }^{14,15,16}$

\section{CONCLUSION}

Urolithiasis and urinary tract infection are two well known risk factors for the development of XPN. Our experience in the present series, demonstrates that low socioeconomic status could be another risk factor for XPN. Early diagnosis and proper treatment of urolithiasis \& urinary tract infection is important to prevent their complications including XGP.

\section{Copyright@ 16 Oct, 2019.}

\section{REFERENCES}

1. Caliskan S, Ozsoy E, Kaba S, Koca O, Ozturk MI. Xanthogranulomatous pyelonephritis. Arch Iran Med.2016; 19(10):712-14.

2. Addison B, Zargar H, Lilic N, Memiless D, Rice M. Analysis of 35 cases of Xanthogranulomatous Pyelonephritis. ANZ J Surg. 2015:85(3); 150-153.

3. Zarif JC, Chalfin HJ, Pierorazio PM, Gorin MA. Characterization of the macrophage infiltrate in a case of Xanthogranulomatous Pyelonephritis. J Clin Urol.2018; $11(3): 226-28$.

4. Chandanwale SS. Xanthogranulomatous pyelonephritis: Unusual clinical presentation. J Fam Med Primary Care. 2013:2; 396-8.

5. Nowicka DO, Lewandowicz KM, Konwerska A, Zachwieja J. Early progression of xanthogranulomatous pyelonephritis in children might be dependent on vimentin expression. Am J Case Rep. 2017; 18:10661072. 
6. Rajesh A, Jakanani G, Mayer N, Mulcahy K. Computed Tomography findings in Xanthgranulomatous Pyelonephritis. J Clin Imaging Sci 2011; $1(2): 45$.

7. Nebot C S, Aliaga S P,Durba A S, Roca M J. Xanthogranulomatous Pyelonephritis in children. Insight Imaging 2018; 31.

8. Ando SDM, Mereno RA, Viana PCC, Yamauchi FI. Extensive renal lipomatosis in xanthogranulomatous pyelonephritis simulating liposarcoma. Int Braz J Urol. 2018; (3):642-44.

9. Begum T, Huq ME, Ahmed M. Xanthogranulomatous pyelonephritis. BMJ Case Rep 2016; (10):1-2.

10. Nawaz H, Khan S, Hussain I, Ahmed S, Khan M, Niazi N. Xanthogranulomatous Pyelonephritis due to calculai: Report of 63 cases \& review of literature. J Pak Med Assoc 2005; 55(9):387-89.

11. Alghazo MA, Ghalayini IF, Matalka II, Alkaisi NS, Khader YS. Xanthogrnulomatous Pyelonephritis: Analysis of 18 cases. Asian J of Sur 2006; 29(4):257-61.
12. Fallah A, Tarakji M, Amuesi J. Xanthogranulomatous pyelonephrits: A retrospective study of 10 cases and review of the literature. Saudi J Kidney Dis Transpl $2001 ; 12: 520-4$.

13. Mseddi MA, Jallouli M, Mejdoub B, Ammar $S$ et al. Xanthgranulomatous Pyelonephriti in children: A 24 case series. Eur Urol Suppl 2016; 15(3):475

14. Shah KJ, Ganpule AP, Kurien A et al. Laparoscopic versus open nephrectomy for Xanthogranulomatous pyelonephritis: An outcome analysis. IJU 2011; 27(4): 470-74.

15. Ma L, Yu Y, Ge G, Li G. Laproscopic nephrectomy outside gerota fascia \& en bloc ligation of renal hilum for management of inflammatory renal diseases. Int Braz J Urol 2018; 44(2):280-87.

16. Stoica I, O'Kelly F, McDerott MB, Quinn FMJ. Xanthogranulomatous pyelonephritis in paediatric cohort (1963-2016): Outcomes from a large single Centre series. J Pediatr Urol 2018; 14(2):169.

\begin{tabular}{|c|c|c|c|}
\hline \multicolumn{4}{|c|}{ AUTHORSHIP AND CONTRIBUTION DECLARATION } \\
\hline Sr. \# & Author(s) Full Name & Contribution to the paper & Author(s) Signature \\
\hline 1 & Masha Khan & 1st Author & a. \\
\hline 3 & Muhammad Anwar & 3rd Author & \\
\hline 4 & Ali Nawaz & 4th Author & \\
\hline 5 & Muhammad Shoaib & 5th Author & \\
\hline 6 & Abdul Samad & 6th Author & \\
\hline 7 & Haq Nawaz & 7th Author & 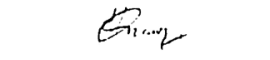 \\
\hline 8 & Yaqoob Zarkoon & 8th Author & \\
\hline 9 & Saadat Khan & 9th Author & 4 \\
\hline
\end{tabular}

